\title{
Efficacy and safety of tigecycline versus levofloxacin for community-acquired pneumonia
}

Cristina Tanaseanu*1, Slobodan Milutinovic ${ }^{2}$, Petre I Calistru ${ }^{3}$, Janos Strausz ${ }^{4}$, Marius Zolubas ${ }^{5}$, Valeriy Chernyak ${ }^{6}$, Nathalie Dartois7, Nathalie Castaing ${ }^{7}$, Hassan Gandjini ${ }^{7}$, C Angel Cooper ${ }^{8}$ for the 313 Study Group

Address: ${ }^{1}$ St. Pantelimon Clinical Emergency Hospital, Bucharest, Romania, ${ }^{2}$ General Hospital Sveti Duh, Zagreb, Croatia, ${ }^{3}$ Clinic of Infectious and Tropical Diseases "Dr. Victor Babes" Bucharest, Romania, ${ }^{4}$ Pulmonology Hospital, Torokbalint, Hungary, ${ }^{5}$ Klaipeda Regional Hospital, Klaipeda, Lithuania, ${ }^{6}$ Cherkassy Regional Hospital, Cherkassy, Ukraine, ${ }^{7}$ Wyeth Research, Paris, France and ${ }^{8}$ Wyeth Research, Collegeville, PA, USA

Email: Cristina Tanaseanu* - cristina.tanaseanu@gmail.com; Slobodan Milutinovic - slobodan.milutinovic@bol-svduh.htnet.hr; Petre I Calistru - pcalistru@yahoo.com; Janos Strausz - strausz@koranyi.hu; Marius Zolubas - zolubas@omni.lt;

Valeriy Chernyak - schevchenko@neocm.com; Nathalie Dartois - dartoin@wyeth.com; Nathalie Castaing - castain@wyeth.com; Hassan Gandjini - gandjih@wyeth.com; C Angel Cooper - cooperc2@wyeth.com

* Corresponding author

Published: 9 September 2009

BMC Pulmonary Medicine 2009, 9:44 doi:10.1 186/I47I-2466-9-44

This article is available from: http://www.biomedcentral.com/I47I-2466/9/44

(C) 2009 Tanaseanu et al; licensee BioMed Central Ltd.

This is an Open Access article distributed under the terms of the Creative Commons Attribution License (http://creativecommons.org/licenses/by/2.0), which permits unrestricted use, distribution, and reproduction in any medium, provided the original work is properly cited.
Received: 6 January 2009

Accepted: 9 September 2009

\begin{abstract}
Background: Tigecycline, an expanded broad-spectrum glycylcycline, exhibits in vitro activity against many common pathogens associated with community-acquired pneumonia (CAP), as well as penetration into lung tissues that suggests effectiveness in hospitalized CAP patients. The aim of the present study was to compare the efficacy and safety of intravenous (IV) tigecycline with IV levofloxacin in hospitalized adults with CAP.
\end{abstract}

Methods: In this prospective, double-blind, non-inferiority phase 3 trial, eligible patients with a clinical diagnosis of CAP supported by radiographic evidence were stratified by Fine Pneumonia Severity Index and randomized to tigecycline or levofloxacin for 7-14 days of therapy. Co-primary efficacy endpoints were clinical response in the clinically evaluable (CE) and clinical modified intentto-treat (c-mlTT) populations at test-of-cure (Day 10-2I post-therapy).

Results: Of the 428 patients who received at least one dose of study drug, $79 \%$ had CAP of mildmoderate severity according to their Fine score. Clinical cure rates for the CE population were $\mathbf{8 8 . 9 \%}$ for tigecycline and $\mathbf{8 5 . 3 \%}$ for levofloxacin. Corresponding c-mITT population rates were $83.7 \%$ and $81.5 \%$, respectively. Eradication rates for Streptococcus pneumoniae were $92 \%$ for tigecycline and $89 \%$ for levofloxacin. Nausea, vomiting, and diarrhoea were the most frequently reported adverse events. Rates of premature discontinuation of study drug or study withdrawal because of any adverse event were similar for both study drugs.

Conclusion: These findings suggest that IV tigecycline is non-inferior to IV levofloxacin and is generally well-tolerated in the treatment of hospitalized adults with CAP.

Trial registration: NCT0008I575 


\section{Background}

Community-acquired pneumonia (CAP) occurs in approximately one to five per 1000 of the adult population per year [1-3] and is associated with rates of mortality ranging from a low of 5\% up to $30 \%-50 \%$ for patients with multiple comorbidities and requiring intensive care $[2,4,5]$. Streptococcus pneumoniae (the most common etiologic agent), nontypeable Haemophilus influenzae, and the atypical organisms (i.e., Mycoplasma pneumoniae, Chlamydia pneumoniae, and Legionella pneumophila) are the most frequently isolated pathogens from patients of any age who require hospitalization for CAP $[2,5-10]$. Rates of multidrug-resistant $S$. pneumoniae have been reported to be $>30 \%$ worldwide and $H$. influenzae beta-lactamase production varies by country, ranging from $12 \%$ to $27 \%$ [1114].

Initial antimicrobial treatment for patients with CAP should provide appropriate coverage against the most common causative organisms, including resistant strains, while evaluating whether monotherapy or combination therapy is required. For hospitalized patients who do not require admission to the intensive care unit (ICU), the most recent guidelines published by several authorities recommend the combination of an extended-spectrum cephalosporin or beta-lactam/beta-lactamase inhibitor combination with the option of adding a macrolide or monotherapy with a newer fluoroquinolone [5,7-10].

Tigecycline, a first-in-class, expanded broad-spectrum glycylcycline, demonstrates in vitro activity against many commonly encountered respiratory bacteria, including multiple resistant gram-positive, gram-negative, anaerobic, and "atypical" bacteria such as multidrug-resistant $S$. pneumoniae and beta-lactamase producing $H$. influenzae [15]. In this first phase 3 study in CAP with tigecycline, the primary objective was to compare the efficacy and safety of intravenous (IV) tigecycline with IV levofloxacin in the treatment of patients with CAP requiring hospitalization. Levofloxacin was chosen as the comparator because it is commonly prescribed worldwide and it is recommended in guidelines for the treatment of CAP $[5,8-10]$.

\section{Methods}

\section{Study design and patient enrolment criteria}

A prospective, double-blind (third-party unblinded), randomized, multicentre, phase 3 study was conducted from January 2004 to January 2005 at 62 centres in 20 countries in Europe, Africa, and the Asia Pacific region. Approximately 400 subjects were enrolled to obtain 240 clinically evaluable subjects and to ensure with $90 \%$ probability that the lower bound of a two-sided 95\% confidence interval for the true difference in efficacy would not be less than $-15 \%$. The protocol was reviewed and approved by each investigator's independent ethics committee or insti- tutional review board in accordance with local regulations and good clinical practices. Written informed consent was to be obtained from each patient or his or her guardian before commencement of any study-specific procedure.

Subjects were stratified at randomization by the Fine Pneumonia Severity Index score (V, IV, III, or less than III) [16]. In a post-hoc analysis, the severity of each subject's pneumonia was also categorized using an estimate of the CURB-65 prediction severity tool, using a notation of "altered mental status" under medical history for "confusion" [17]. Subjects were assigned in a 1:1 ratio to treatment using a computerized system of automated telephone randomization, to receive either IV tigecycline (initial 100-mg dose given by infusion over a 60-minute period, followed by $50 \mathrm{mg}$ IV every 12 hours) or levofloxacin (500 mg once-daily or twice-daily based on investigator's discretion, administered over a 60-minute period; or for subjects with creatinine clearance $20-49 \mathrm{~mL} /$ min, an initial 500-mg dose followed by $250 \mathrm{mg}$ once- or twice-daily) for at least 7 days, unless a clinical failure, and up to a maximum of 14 days. An unblinded third party prepared the masked test articles and an unblinded nurse administered the test article. The person(s) responsible for preparing and/or administering the test article were not involved in the assessment or evaluation of the subject for safety or efficacy. Each subject's blinded data set was reviewed to ensure the accuracy and integrity of the data.

\section{Patient population}

Male or non-pregnant/non-lactating female patients $\geq 18$ years of age (in Bulgaria only from 18 to $\leq 70$ years of age due to local requirement) hospitalized with clinical signs and symptoms of CAP who required initial parenteral therapy for at least 7 days were considered for enrolment. Each patient was to have fever within 24 hours of randomization (oral temperature $>38^{\circ} \mathrm{C} / 100.4^{\circ} \mathrm{F}$, axillary temperature $>38.1^{\circ} \mathrm{C} / 100.6^{\circ} \mathrm{F}$, tympanic membrane temperature $>38.5^{\circ} \mathrm{C} / 101.2^{\circ} \mathrm{F}$, or a rectal/core temperature $\geq$ $39^{\circ} \mathrm{C} / 102.2^{\circ} \mathrm{F}$ ) or hypothermia (core temperature $<35^{\circ} \mathrm{C} / 95^{\circ} \mathrm{F}$ ). Each patient also was to have at least two of the following signs and symptoms consistent with CAP: cough with production of purulent or mucopurulent sputum; auscultatory findings on pulmonary examination suggestive of pulmonary consolidation (dullness to percussion, rales/rhonchi, or bronchial breath sounds); dyspnoea or tachypnoea; white blood cell (WBC) count $>10,000 / \mathrm{mm}^{3}$, or $>15 \%$ immature neutrophils (bands), and/or leucopoenia with a total WBC count $<4500 / \mathrm{mm}^{3}$; and hypoxemia $\left(\mathrm{PO}_{2}<60 \mathrm{~mm} \mathrm{Hg}\right.$ or oxygen saturation $<90 \%$ while the subject was breathing room air). Radiologically-confirmed evidence of a new or progressive infiltrate(s) consistent with bacterial pneumonia within 48 hours before receiving the first dose of study drug was also mandatory. 
Key exclusion criteria included: hospitalization within 14 days before the onset of symptoms; residence in a longterm care facility $\geq 14$ days before the onset of symptoms; sustained shock or required treatment in an intensive care unit; known or suspected concomitant bacterial infection requiring treatment with an additional systemic antibacterial agent; received more than one dose of systemic antibacterial therapy (or received a once-daily antibiotic) to treat this episode of CAP prior to receiving the first dose of study drug, unless a clinical failure; and known or suspected Pseudomonas, Pneumocystis carinii, Legionella pneumonia, or tuberculosis infection.

\section{Clinical evaluations}

Eligible patients were evaluated, and clinical signs and symptoms recorded at serial visits: baseline (within 24 hours of first study drug dose), during treatment, early follow-up (Day 2-4 post-therapy), and test-of-cure (Day 1021 post-therapy). Pulse oximetry and/or arterial blood gases were obtained at baseline, end of therapy, early follow-up, and at the test-of-cure visits. Chest $\mathrm{x}$-rays were obtained at baseline (within 48 hours of receiving first dose of study drug) and were repeated at the test-of-cure visit. Clinical responses were graded as cure, failure, or indeterminate at the test-of-cure assessment.

\section{Microbiologic evaluations}

Sputum samples, when available, were collected prior to initiation of study drug therapy and submitted to a local laboratory for Gram staining, culture, and susceptibility testing. Specimens obtained by deep expectoration or nasotracheal aspiration were considered appropriate for culture if the Gram stain revealed $<10$ squamous epithelial cells and $>25$ leukocytes/low-power field. Blood specimens (2 sets at least 15 minutes apart from 2 different sites) were to be drawn for culture at enrolment, and if positive were to be repeated at day 3 and at the discretion of the investigator until confirmed negative, or if the subject was a treatment failure. Urine specimens were collected at baseline for Legionella and pneumococcal urinary antigens. Serology for Chlamydia, Mycoplasma, and Legionella was to be obtained for all patients at baseline and $6 \pm 2$ weeks after the baseline collection of blood samples.

All aerobic and anaerobic bacterial isolates, regardless of the source of cultured material, were to be identified and tested at the investigator's laboratory and then confirmed at a central laboratory (Covance Central Laboratory Services, Inc., Geneva, Switzerland) according to standard procedures.

\section{Safety and tolerability assessments}

Each patient who received at least one dose of study drug was evaluated for safety (modified intent-to-treat [mITT] population) based on medical history and physical examinations, reports of clinical adverse events (AEs), and findings from 12-lead electrocardiograms (ECGs) and serum chemistry, haematology, and coagulation tests. Adverse events were to be recorded throughout the study period, up to and including the test-of-cure visit (or 14 days after the last dose of study drug, whichever was greater). Before unblinding, the investigator categorized the severity of each adverse event and the potential for relationship to the study drug. Severity of nausea and vomiting was categorized according to the National Cancer Institute Common Toxicity Criteria: grade 1 (mild), 2 (moderate), 3 (severe), and 4 (life-threatening). Serious adverse events (i.e., those that were life-threatening, led to prolongation of the existing hospitalization, or caused persistent or significant disability or incapacity, or death) were also recorded.

\section{Statistical analysis}

The primary efficacy endpoint of the study was the clinical response at the test-of-cure visit (10-21 days after therapy) for the co-primary clinically evaluable (CE) and clinical modified ITT (c-mITT) populations. Secondary analyses included clinical response rates in the microbiologically evaluable (ME) and microbiologic modified ITT (mmITT) populations, monomicrobial versus polymicrobial infections, and by isolate, as well as microbiologic response at the test-of-cure visit by patient and isolate.

Statistical analysis was performed by the Clinical Biostatistics Department of Wyeth Research, Collegeville, PA. Categorical baseline demographic and medical variables were analyzed using the Fisher exact test. Continuous variables were compared using a one-way analysis of variance (ANOVA) model with treatment as a factor. Betweengroup comparisons of adverse events were analyzed by using the Fisher exact test. For laboratory tests, vital signs, and ECG results, within-group changes from baseline were analyzed by using a paired t-test and between-group comparisons were made by using the analysis of covariance, adjusting for baseline value. The difference between treatment groups in the percentage of premature discontinuation from study drug was evaluated by using a twosided Fisher exact test.

Non-inferiority of tigecycline compared with levofloxacin was evaluated for clinical response by using a two-sided 95\% confidence interval for the true difference in efficacy (tigecycline minus levofloxacin) adjusted for the stratification variable (Fine Pneumonia Severity Index score) used at the time of randomization. Non-inferiority was concluded if the lower limit of the two-sided $95 \% \mathrm{CI}$ was greater than or equal to $-15 \%$. For all subpopulation analyses (e.g., monomicrobial versus polymicrobial infection), an adjusted difference between treatment groups 
with its 95\% CI was calculated from a generalized linear model with a binomial probability function and an identity link (Proc GENMOD).

\section{Results}

A total of 449 patients were screened for study participation, of which 434 were randomly assigned to receive tigecycline or levofloxacin, constituting the intent-to-treat (ITT) population, and 428 received at least 1 dose of study medication, constituting the modified ITT (mITT) population (Figure 1).

\section{Demographics and baseline medical characteristics}

Demographic and baseline medical characteristics for the mITT population are summarized in Table 1 and were similar for the two treatment groups, with a mean age of $49.8 \pm 17.7$ years and a slight predominance of male enrolment (62\%). All subjects required hospitalization although most subjects were considered to have mildmoderate CAP (79\% with Fine score I-III). Demographic and baseline medical characteristics in the CE population displayed similar results (Table 1).

\section{Clinical efficacy}

The clinical efficacy of tigecycline was found to be noninferior $(P<0.001)$ to that of levofloxacin in the CE population, with clinical cure rates of $88.9 \%$ for tigecycline versus $85.3 \%$ for levofloxacin (adjusted difference of 3.6, $95 \%$ CI $-4.5,11.8 ; P=0.4025$; Table 2 ). Analysis of clinical response at the test-of-cure assessment for the CE population by Fine score category also showed the noninferiority of tigecycline compared with levofloxacin. Similar findings were observed for clinical response using estimated CURB-65 score distributions (Table 2). Clinical cure rates for patients with diabetes were 100\% (17/17) for tigecycline- vs. 75\% (12/16) for levofloxacin-treated patients. Similar cure rates were reported for subjects with impaired renal function (i.e., creatinine clearance $\leq 70$ $\mathrm{mL} / \mathrm{min}$ ): $91.3 \%$ (42/46) for tigecycline and 78.3\% (36/ 46) for levofloxacin. Noninferiority of tigecycline was also demonstrated in the $c$-mITT population $(P<0.001)$, with clinical cure rates of $83.7 \%$ for tigecycline versus $81.5 \%$ for levofloxacin (adjusted difference of 2.0, 95\% CI -5.5, 9.6; $P<0.6269$ ). For both the ME and m-mITT populations, tigecycline was also efficacious and statistically noninferior to levofloxacin. When analyzed by the type of infection (polymicrobial and monomicrobial) for the $\mathrm{ME}$ and m-mITT populations, the results were generally similar within each of the treatment groups, and no significant differences in cure rates were observed between the two treatment groups (Table 3).

In the tigecycline treatment group, the clinical cure rate for patients with bacteremia (ME population, 83.3\%; 10/12) was similar to those who did not have bacteremia $(91.9 \%$;
68/74) at baseline. Corresponding rates for the levofloxacin group were $60 \%(3 / 5)$ and $91.3 \%(73 / 80)$, respectively. Most of the cases of bacteremia were caused by $S$. pneumoniae. In the tigecycline treatment group, the cure rate for subjects with $S$. pneumoniae bacteremia (ME population) was $90.9 \%(10 / 11)$, which was similar to those who did not have bacteremia $(90.7 \%$; 68/75). Corresponding rates for the levofloxacin group were 60\% (3/ 5) and $91.3 \%(73 / 80)$, respectively.

\section{Microbiologic efficacy}

Eradication rates (generally presumed, based on clinical response) at the test-of-cure visit for common respiratory pathogens (defined by respiratory culture, urinary antigen, or serology) within the ME population were similar between the two treatment groups (Table 4). For S. pneumoniae, the most common isolate, eradication rates were similar for tigecycline (92\%) and levofloxacin (89\%). Both study drugs eradicated $100 \%$ of penicillin-intermediate $(n=8)$ and penicillin-resistant $(n=5)$ strains. $M$. pneumoniae, the most commonly identified atypical organism, was eradicated in $96 \%(24 / 25)$ of tigecyclineand $92 \%$ (22/24) of levofloxacin-treated patients. There were no obvious differences in the eradication rates of other organisms, albeit the number of isolates was generally small.

\section{Susceptibility data}

Pretherapy in vitro activity against baseline isolates for tigecycline and levofloxacin for the ME population are outlined in Table 5 . The $\mathrm{MIC}_{90}$ for tigecycline against the common respiratory pathogens was $\leq 1.0 \mu \mathrm{g} / \mathrm{mL}$. Specifically, the mean $\mathrm{MIC}_{90}$ for tigecycline against $S$. pneumoniae (all isolates) was $0.06 \mu \mathrm{g} / \mathrm{mL}$. No patients were identified with decreased susceptibility to tigecycline.

\section{Safety and tolerability}

Regardless of study drug causality or severity, the frequency and distribution of treatment-emergent adverse events (TEAEs) occurring in at least 3\% of patients in either treatment group is outlined in Table 6 . Significantly more tigecycline-treated patients $(135 ; 62.5 \%)$ reported one or more TEAEs compared with levofloxacin (100; $47.2 \%)(P=0.002)$. Significantly more patients in the tigecycline group reported nausea (26.9\% tigecycline versus $8.5 \%$ levofloxacin, $P<0.001)$, vomiting $(16.7 \%$ tigecycline versus $6.6 \%$ levofloxacin, $P=0.001)$, and leukocytosis (6.9\% tigecycline versus $0.9 \%$ levofloxacin, $P$ $=0.002$ ), while hypokalaemia was reported significantly more frequently in the levofloxacin group $(0.5 \%$ tigecycline versus $3.8 \%$ levofloxacin, $P=0.019)$. The majority of nausea and vomiting adverse events were reported as mild to moderate in severity (grades 1 or 2 ). Severe (grade 3 ) nausea and/or vomiting occurred in 3 (1.4\%) tigecyclinetreated and $2(1.0 \%)$ levofloxacin-treated patients. In the 


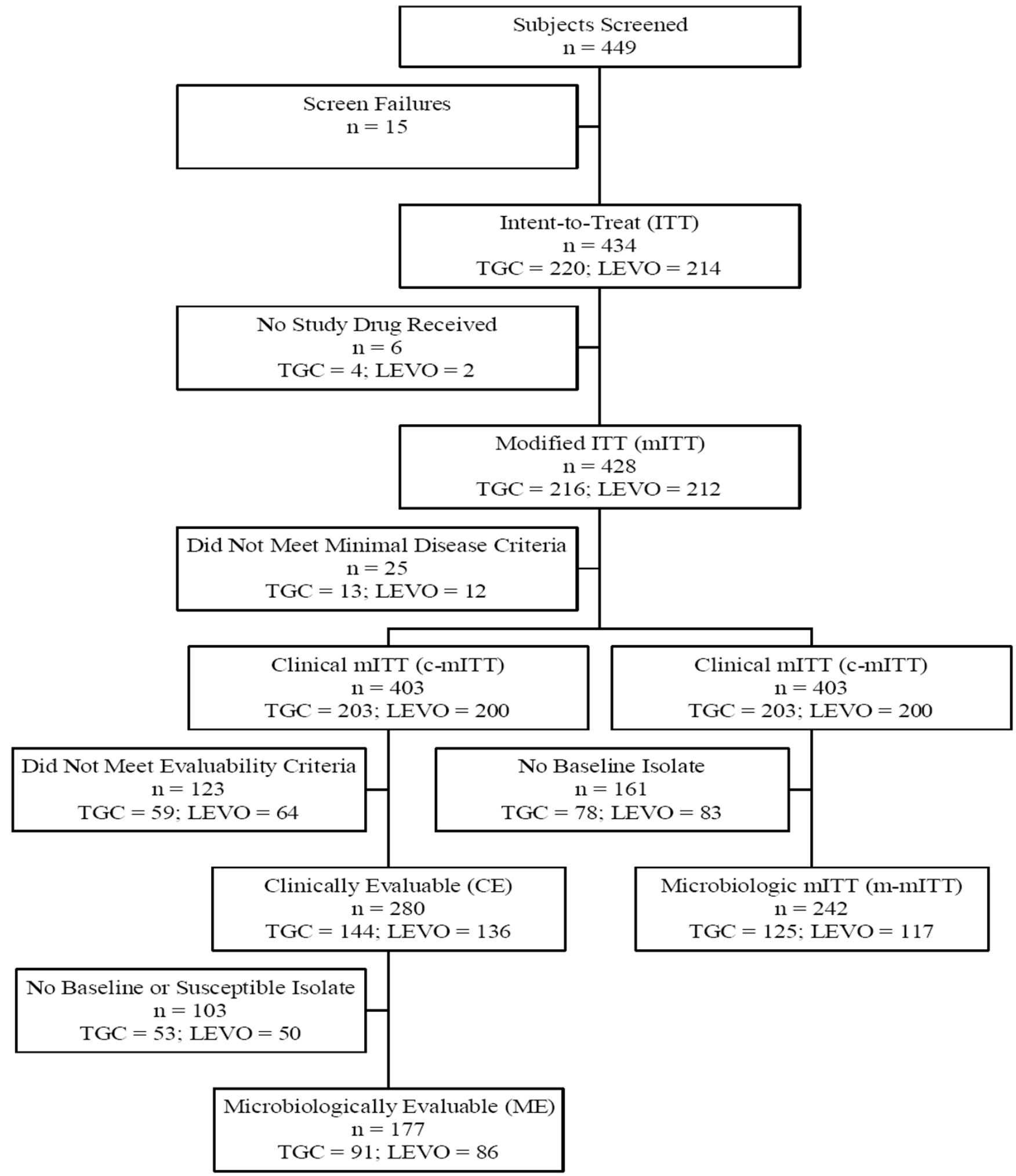

Figure I (see legend on next page) 
Figure I (see previous page)

Flow diagram: disposition of patients. Patients randomized were included in the intent-to-treat (ITT) population. Those who received at least one dose of study drug comprised the modified ITT (mITT) population, and patients in the mITT population who had clinical evidence of CAP by meeting the minimal disease criteria made up the clinical modified ITT (c-mITT) population. The microbiologic modified intent-to-treat (m-mITT) population consisted of c-mlTT subjects who had I or more baseline isolates identified. Patients in the c-mITT population were considered to be clinically evaluable (CE) if they satisfied inclusion and exclusion criteria, received no more than one dose of a non-once daily non-study antibacterial agent (single agent or combination therapy) to treat the current episode of CAP before the first dose of study drug, did not receive other concomitant systemic antimicrobial therapy unless a treatment failure, received at least 2 full days of study drug if clinical failure or 5 full days of study drug if clinical cure, were adherent with therapy (i.e., $\geq 80 \%$ but $\leq 120 \%$ of medication administered), had an assessment of cure or failure at the test-of-cure visit (I0-2I days after the last dose of therapy), and the study blind was maintained. The microbiologically evaluable (ME) population included CE patients for whom at least one isolate was identified from the baseline culture that was susceptible to both test drugs and who had a microbiologic response that could be classified as eradication, persistence, or superinfection at the test-of-cure visit.

tigecycline group, the median time to onset of nausea and/or vomiting was approximately 1.1 days. The total duration of nausea or vomiting occurred over a median of approximately 2.5 days while on tigecycline therapy. Significantly more tigecycline-treated subjects $(46 ; 21.3 \%)$ received concomitant medications for nausea/vomiting compared with the levofloxacin-treated subjects (11; $5.2 \%)(P \leq 0.0001)$. There was no significant difference in the discontinuation rate from study medication between the treatment groups for nausea or vomiting.
Drug-related adverse events (as assessed by the investigator) were reported in $44.4 \%$ of tigecycline- and $29.2 \%$ of levofloxacin-treated subjects $(P<0.001$; Table 7$)$. Drugrelated digestive system adverse events were the most frequently reported AEs in both treatment groups (32.4\% for tigecycline versus $16.0 \%$ for levofloxacin; $P<0.001)$. Nausea and vomiting occurred more commonly in tigecyclinetreated subjects (25\% and $14.4 \%$, respectively) compared with levofloxacin-treated subjects $(7.5 \%$ and $4.7 \%$, respectively; both $P<0.001)$.

Table I: Baseline Demographic and Medical Characteristics*

\begin{tabular}{|c|c|c|c|c|}
\hline \multirow[b]{3}{*}{ Characteristic } & \multicolumn{4}{|c|}{ Study Population } \\
\hline & \multicolumn{2}{|c|}{ mITT } & \multicolumn{2}{|c|}{ CE } \\
\hline & $\begin{array}{l}\text { Tigecycline } \\
(n=216)\end{array}$ & $\begin{array}{l}\text { Levofloxacin } \\
\qquad(n=212)\end{array}$ & $\begin{array}{l}\text { Tigecycline } \\
(n=144)\end{array}$ & $\begin{array}{l}\text { Levofloxacin } \\
\quad(n=136)\end{array}$ \\
\hline Male, n (\%) & $|3|(6 \mid)$ & $133(63)$ & $91(63)$ & $87(64)$ \\
\hline \multicolumn{5}{|l|}{ Race, n (\%) } \\
\hline White & $189(88)$ & $184(87)$ & $129(90)$ & $117(86)$ \\
\hline Black & $2(<1)$ & $4(2)$ & - & $3(2)$ \\
\hline Asian & $5(2)$ & $7(3)$ & $3(2)$ & $7(5)$ \\
\hline Other & $20(9)$ & $17(8)$ & $12(8)$ & $9(7)$ \\
\hline Mean age $\pm S D$, years (range) & $49.9 \pm 18.1(17--92)$ & $49.7 \pm 17.4(18--85)$ & $52.8 \pm 16.9(18--89)$ & $50.4 \pm 17.0(18--85)$ \\
\hline \multicolumn{5}{|c|}{ Fine Pneumonia Severity Score Index, n (\%) } \\
\hline I & $32(15)$ & 41 (19) & $18(13)$ & $23(17)$ \\
\hline II & $79(37)$ & $61(29)$ & $49(34)$ & $40(29)$ \\
\hline III & $59(27)$ & $66(31)$ & $40(28)$ & $42(31)$ \\
\hline IV & $44(20)$ & $42(20)$ & $35(24)$ & $30(22)$ \\
\hline V & $2(<1)$ & $2(<1)$ & $2(1)$ & $I(<1)$ \\
\hline Prior antibiotic failure, $\mathrm{n}(\%)$ & $44(20)$ & $55(26)$ & $9(6)$ & $15(11)$ \\
\hline \multicolumn{5}{|c|}{ Presence of underlying medical conditions } \\
\hline COPD, n (\%) & $14(7)$ & $19(9)$ & $10(7)$ & $14(10)$ \\
\hline Diabetes mellitus, $\mathrm{n}(\%)$ & $24(\mathrm{II})$ & $25(12)$ & $17(12)$ & $16(12)$ \\
\hline Alcohol abuse, $n(\%)$ & $14(7)$ & $10(5)$ & $10(7)$ & $7(5)$ \\
\hline Neoplastic disease, $\mathrm{n}(\%)$ & - & $2(<1)$ & - & $2(2)$ \\
\hline Liver disease, $n(\%)$ & $15(7)$ & $8(4)$ & $10(7)$ & $4(3)$ \\
\hline Congestive heart disease, $\mathrm{n}(\%)$ & $15(7)$ & $15(7)$ & $13(9)$ & $10(7)$ \\
\hline Cerebrovascular disease, $\mathrm{n}(\%)$ & $12(6)$ & $17(8)$ & $8(6)$ & $13(10)$ \\
\hline
\end{tabular}

*There were no statistically significant differences between the treatment groups for demographic or baseline medical characteristics for both the mITT and CE populations. 
Table 2: Cure Rates at the Test-of-Cure Visit*

\begin{tabular}{|c|c|c|c|c|c|c|c|}
\hline & \multicolumn{2}{|c|}{ Tigecycline } & \multicolumn{2}{|c|}{ Levofloxacin } & \multicolumn{3}{|c|}{ Difference (Tigecycline - Levofloxacin) } \\
\hline & $n / \mathbf{N}$ & $\%(95 \% \mathrm{Cl})$ & $n / \mathbf{N}$ & $\%(95 \% \mathrm{Cl})$ & $\%(95 \% \mathrm{Cl})$ & $\begin{array}{l}\text { Test for Non- } \\
\text { inferiority } \\
\text { p-Value }\end{array}$ & $\begin{array}{l}\text { Test for } \\
\text { Difference } \\
\text { p-Value }\end{array}$ \\
\hline CE, Overall & $128 / 144$ & $88.9(82.6,93.5)$ & $116 / 136$ & $85.3(78.2,90.8)$ & $3.6(-4.5,11.8)$ & $<0.001$ & 0.4025 \\
\hline Fine $<$ III & $60 / 67$ & $89.6(79.7,95.7)$ & $55 / 63$ & $87.3(76.5,94.4)$ & $2.3(-10.3,14.8)$ & 0.0026 & 0.8993 \\
\hline Fine III & $34 / 40$ & $85.0(70.2,94.3)$ & $35 / 42$ & $83.3(68.6,93.0)$ & $1.7(-16.6,19.9)$ & 0.0388 & 1.0000 \\
\hline Fine IV & $32 / 35$ & $91.4(76.9,98.2)$ & $25 / 30$ & $83.3(65.3,94.4)$ & $8.1(-11.2,27.4)$ & 0.0079 & 0.5463 \\
\hline Fine $\mathrm{V}$ & $2 / 2$ & $100.0(15.8,100.0)$ & $1 / 1$ & $100.0(2.5,100.0)$ & $0(-75.0,75.0)$ & - & - \\
\hline $\begin{array}{l}\text { Estimated CURB-65 } \\
0-1\end{array}$ & $87 / 97$ & $89.7(81.9,94.9)$ & $79 / 93$ & $84.9(76.0,91.5)$ & $4.7(-5.6,15.3)$ & & \\
\hline $\begin{array}{l}\text { Estimated CURB-65 } \\
2\end{array}$ & $31 / 36$ & $86.1(70.5,95.3)$ & $30 / 34$ & $88.2(72.5,96.7)$ & $-2.1(-20.3,16.6)$ & & \\
\hline CURB-65 $\geq 3$ & $10 / 11$ & $90.9(58.7,99.8)$ & $7 / 9$ & $77.8(40.0,97.2)$ & $13.1(-25.3,51.7)$ & & \\
\hline c-mlTT & $170 / 203$ & $83.7(77.9,88.5)$ & $163 / 200$ & $81.5(75.4,86.6)$ & $2.0(-5.5,9.6)$ & $<0.001$ & 0.6269 \\
\hline
\end{tabular}

\begin{abstract}
*At the test-of-cure visit, each patient's response was categorized as one of the following: Cure---All signs and symptoms of pneumonia present at baseline were improved or resolved at test-of-cure with no worsening or appearance of new signs and symptoms of pneumonia and no requirement for further antibiotic therapy. Chest radiographs were improved or not worse. Failure---Persistence or worsening in signs and symptoms of the acute process with either failure to show improvement in the clinical findings, initial improvement in signs and symptoms followed by clinically significant worsening before the test-of-cure assessment, additional antimicrobial therapy required, progression of chest radiograph abnormalities, or death after study day 2 because of pneumonia; or Indeterminate---the patient was lost to follow-up, or died within 2 days after the first dose of study drug for any reason, or died after 2 days because of noninfectious-related reasons or infection other than pneumonia (as judged by the investigator). $\mathrm{CE}=$ clinically evaluable population; c-mITT = clinical-modified intent-to-treat population.
\end{abstract}

Thirty-nine patients reported a serious adverse event during the study period (18 tigecycline, 21 levofloxacin). Only one serious adverse event (nausea) in a tigecyclinetreated patient was considered related to the study drug; the event resolved. A total of twelve (12) patients died during the study: 7 in the tigecycline group and 5 in the levofloxacin treatment group. All of the deaths were reported by investigators as either probably not or definitely not related to the study drug.

There was no statistically significant difference between tigecycline and levofloxacin in the number of patients in the mITT population who prematurely discontinued the study drug $(14 ; 6.5 \%$ tigecycline versus $17 ; 8.0 \%$ levofloxacin) or withdrew because of any adverse event (4; $1.9 \%$ tigecycline versus $5,2.4 \%$ levofloxacin). Mean change from baseline in laboratory, vital sign, and ECG parameters was generally small.

\section{Discussion}

This multinational, double-blind, randomized, phase 3 clinical trial demonstrated that IV tigecycline (100 mg initial dose, followed by $50 \mathrm{mg}$ every 12 hours) is as effective as IV levofloxacin (500 mg once- or twice-daily) for the treatment of hospitalized adult patients with CAP. For the 280 clinically evaluable patients, clinical cure rates were $88.9 \%$ for tigecycline and $85.3 \%$ for levofloxacin at the test-of-cure visit, with tigecycline meeting the statistical criteria for non-inferiority compared with levofloxacin, a widely used agent in this setting. These findings were confirmed in the co-primary c-mITT population. We also observed that tigecycline generally achieved good cure

Table 3: Cure Rates by Monomicrobial/Polymicrobial Infection at the Test-of-Cure Visit

\begin{tabular}{|c|c|c|c|c|c|}
\hline & \multicolumn{2}{|c|}{ Tigecycline } & \multicolumn{2}{|c|}{ Levofloxacin } & \multirow{2}{*}{$\begin{array}{c}\text { Difference (Tigecycline -- Levofloxacin) } \\
\%(95 \% \mathrm{Cl})\end{array}$} \\
\hline & $n / N$ & $\%(95 \% \mathrm{Cl})$ & $n / N$ & $\%(95 \% \mathrm{Cl})$ & \\
\hline \multicolumn{6}{|l|}{ ME } \\
\hline Monomicrobial & $53 / 58$ & $91.4(81.0,97.1)$ & $56 / 64$ & $87.5(76.8,94.4)$ & $3.9(-9.0,16.3)$ \\
\hline Polymicrobial & $25 / 28$ & $89.3(71.8,97.7)$ & $20 / 21$ & $95.2(76.2,99.9)$ & $-6.0(-25.1,16.6)$ \\
\hline \multicolumn{6}{|l|}{$\mathrm{m}-\mathrm{mlTT}$} \\
\hline Monomicrobial & $74 / 84$ & $88.1(79.2,94.1)$ & $76 / 88$ & $86.4(77.4,92.8)$ & $1.7(-9.4,12.7)$ \\
\hline Polymicrobial & $28 / 34$ & $82.4(65.5,93.2)$ & $23 / 25$ & $92.0(74.0,99.0)$ & $-9.6(-28.4,12.4)$ \\
\hline
\end{tabular}

ME = microbiologically evaluable population; $\mathrm{m}-\mathrm{mITT}=$ microbiologic-modified intent-to-treat population . 
Table 4: Microbiologic Response for Common Respiratory Pathogens at Test-of-Cure Visit in the ME Population

\begin{tabular}{|c|c|c|c|c|c|c|}
\hline \multirow[b]{2}{*}{ Isolate } & \multicolumn{3}{|c|}{ Tigecycline } & \multicolumn{3}{|c|}{ Levofloxacin } \\
\hline & $\mathbf{n} / \mathbf{N}$ & $\%$ & $(95 \% \mathrm{Cl})$ & $\mathbf{n} / \mathbf{N}$ & $\%$ & $(95 \% \mathrm{CI})$ \\
\hline Streptococcus pneumoniae & $46 / 50$ & 92.0 & $(80.8,97.8)$ & $32 / 36$ & 88.9 & $(73.9,96.9)$ \\
\hline Penicillin-intermediate S. pneumoniae & $3 / 3$ & 100 & $(29.2,100)$ & $5 / 5$ & 100 & $(47.8,100)$ \\
\hline Penicillin-resistant S. pneumoniae & $2 / 2$ & 100 & $(15.8,100)$ & $3 / 3$ & 100 & $(29.2,100)$ \\
\hline Haemophilus influenzae & $8 / 11$ & 72.7 & $(39.0,94.0)$ & $6 / 7$ & 85.7 & $(42.1,99.6)$ \\
\hline Haemophilus parainfluenzae & $5 / 5$ & 100 & $(47.8,100)$ & $9 / 9$ & 100 & $(66.4,100)$ \\
\hline Klebsiella pneumoniae & $4 / 4$ & 100 & $(39.8,100)$ & $7 / 7$ & 100 & $(59.0,100)$ \\
\hline Staphylococcus aureus (all non-MRSA) & $7 / 9$ & 77.8 & $(40.0,97.2)$ & $6 / 6$ & 100 & $(54.1,100)$ \\
\hline Chlamydia pneumoniae & $5 / 5$ & 100 & $(47.8,100)$ & $|I /| \mid$ & 100 & $(71.5,100)$ \\
\hline Mycoplasma pneumoniae & $24 / 25$ & 96.0 & $(79.6,99.9)$ & $22 / 24$ & 91.7 & $(73.0,99.0)$ \\
\hline Legionella pneumophila & $3 / 3$ & 100 & $(29.2,100)$ & $5 / 5$ & 100 & $(47.8,100)$ \\
\hline
\end{tabular}

MRSA: methicillin-resistant Staphylococcus aureus

rates and was very consistent when analyzed by demographic characteristics and co-morbid conditions, and by a variety of risk factors, including the Fine Pneumonia Severity Index [16]. Because bacteremia can be a fatal complication among patients with CAP, it is also encouraging that tigecycline provided an excellent cure rate $(90.9 \%)$ in ME patients with S. pneumoniae bacteremia.

Because most of the microbiologic eradication rates by patient were presumed based on clinical response, little can be said about this secondary endpoint. ME subjects with $S$. pneumoniae isolates, the most common isolate by far, achieved clinical cures in $92 \%$ and $86 \%$ of tigecyclineand levofloxacin-treated subjects, respectively. Although the number of penicillin-intermediate or -resistant strains was low, both antimicrobials eradicated $100 \%$ of penicillin-intermediate $(n=8)$ and penicillin-resistant $(n=5)$ strains, although 1 of the 3 levofloxacin-treated subjects with penicillin-resistant $S$. pneumoniae did not achieve a clinical cure. High clinical cure/eradication rates were achieved against $M$. pneumoniae, the second most commonly identified organism, with both treatments; the cure rates for the ME population were $96 \%$ and $92 \%$, respectively. Good cure rates were generally achieved with tigecycline against a number of other commonly encountered respiratory pathogens, including Legionella pneumophila (although there were small numbers of subjects with this pathogen), supporting in vitro observations that tigecycline has broad-spectrum activity against isolates frequently encountered in patients with CAP $[15,18,19]$.

The current study also confirmed the in vitro activity of tigecycline against respiratory isolates, with $\mathrm{MIC}_{90} \mathrm{~s}$ of $\leq$ $1.0 \mu \mathrm{g} / \mathrm{mL}$ against the common gram-positive and gramnegative respiratory aerobes. Tigecycline has good in vitro activity against resistant organisms (e.g., penicillin-resistant $S$. pneumoniae, $)[15,18,19]$. It is now recognized that tigecycline binds to bacterial ribosomes in a novel way that allows it to overcome tetracycline resistance due to ribosomal protection [20].

Tigecycline and levofloxacin were generally well-tolerated in the current trial. Tigecycline-treated patients reported significantly more treatment-emergent adverse events overall $(62.5 \%$ versus $47.2 \% ; P=0.002)$, as well as adverse events considered drug-related by the investigator (44.4\% versus $29.2 \% ; P<0.001$ ). As has been reported in other tigecycline studies, gastrointestinal adverse events were the most frequently reported treatment-emergent and drug-related adverse events. For treatment-emergent

Table 5: MIC Range, and $M_{I} C_{50}$ and $M I C_{90}$ Values of Common Respiratory Pathogens in the ME Population

\begin{tabular}{|c|c|c|c|c|c|c|c|c|}
\hline \multirow[b]{2}{*}{ Isolate } & \multicolumn{4}{|c|}{ Tigecycline } & \multicolumn{4}{|c|}{ Levofloxacin } \\
\hline & $\mathbf{n}$ & MIC Range & $\mathbf{M I C}_{50}$ & $\mathbf{M I C}_{90}$ & $\mathbf{n}$ & MIC Range & $\mathbf{M I C}_{50}$ & MIC $_{90}$ \\
\hline $\begin{array}{l}\text { Streptococcus pneumoniae } \\
\text { (penicillin susceptible) }\end{array}$ & 45 & $0.030,0.120$ & 0.060 & 0.060 & 45 & $0.250,2.000$ & 1.000 & 1.000 \\
\hline Penicillin-intermediate S. pneumoniae & 8 & $0.060,0.060$ & NA & NA & 8 & $1.000,1.000$ & NA & NA \\
\hline Penicillin-resistant S. pneumoniae & 5 & $0.060,0.060$ & NA & NA & 5 & $1.000,2.000$ & NA & NA \\
\hline Haemophilus influenzae & 18 & $0.120,0.500$ & 0.250 & 0.500 & 18 & $0.120,0.120$ & 0.120 & 0.120 \\
\hline Haemophilus parainfluenzae & 13 & $0.250,0.500$ & 0.500 & 0.500 & 13 & $0.120,0.120$ & 0.120 & 0.120 \\
\hline Klebsiella pneumoniae & 11 & $0.250,2.000$ & 0.500 & 1.000 & 11 & $0.120,0.500$ & 0.120 & 0.120 \\
\hline Staphylococcus aureus (all non-MRSA) & 15 & $0.120,0.250$ & 0.120 & 0.120 & 15 & $0.120,0.250$ & 0.120 & 0.250 \\
\hline
\end{tabular}

MRSA: methicillin-resistant Staphylococcus aureus 
Table 6: Treatment-Emergent Adverse Events that Occurred in $\geq 3 \%$ of Patients (mITT Population), Number of Patients (\%)

\begin{tabular}{|c|c|c|c|c|c|c|c|}
\hline \multirow{2}{*}{$\begin{array}{l}\text { Body System } \\
\text { Adverse Event } \\
\text { Any adverse event }\end{array}$} & \multicolumn{2}{|c|}{$\begin{array}{c}\text { Tigecycline } \\
(n=2 \text { I 6) } \\
\text { N (\%) }\end{array}$} & \multicolumn{2}{|c|}{$\begin{array}{l}\text { Levofloxacin } \\
\qquad \begin{array}{c}(n=2 \mid 2) \\
n(\%)\end{array}\end{array}$} & \multicolumn{2}{|c|}{$\begin{array}{c}\text { Total } \\
\left(\begin{array}{l}N=428) \\
N(\%)\end{array}\right.\end{array}$} & \multirow{2}{*}{$\begin{array}{c}\begin{array}{c}\text { Fisher Exact } \\
\text { P-Value }\end{array} \\
0.002^{*}\end{array}$} \\
\hline & 135 & 62.5 & 100 & 47.2 & 235 & 54.9 & \\
\hline Body as a whole & 29 & 13.4 & 26 & 12.3 & 55 & 12.9 & 0.774 \\
\hline Headache & 10 & 4.6 & 4 & 1.9 & 14 & 3.3 & 0.173 \\
\hline Digestive system & 82 & 38.0 & 44 & 20.8 & 126 & 29.4 & $<0.00 I^{*}$ \\
\hline Diarrhoea & 16 & 7.4 & 17 & 8.0 & 33 & 7.7 & 0.858 \\
\hline Nausea & 58 & 26.9 & 18 & 8.5 & 76 & 17.8 & $<0.001 *$ \\
\hline Vomiting & 36 & 16.7 & 14 & 6.6 & 50 & 11.7 & $0.001 *$ \\
\hline Haemic and lymphatic system & 31 & 14.4 & 11 & 5.2 & 42 & 9.8 & $0.002 *$ \\
\hline Leukocytosis & 15 & 6.9 & 2 & 0.9 & 17 & 4.0 & $0.002 *$ \\
\hline Thrombocythaemia & 11 & 5.1 & 4 & 1.9 & 15 & 3.5 & 0.112 \\
\hline Metabolic and nutritional & 20 & 9.3 & 26 & 12.3 & 46 & 10.7 & 0.351 \\
\hline ALT/SGPT increased & 4 & 1.9 & 9 & 4.2 & 13 & 3.0 & 0.169 \\
\hline AST/SGOT increased & 4 & 1.9 & 7 & 3.3 & 11 & 2.6 & 0.378 \\
\hline Hypokalaemia & I & 0.5 & 8 & 3.8 & 9 & 2.1 & $0.019 *$ \\
\hline
\end{tabular}

Abbreviation: ALT/SGPT = alanine aminotransferase (serum glutamic pyruvic transaminase); AST/SGOT = aspartate aminotransferase/serum glutamic oxaloacaetic transaminase.

Some subjects had more than I treatment-emergent adverse event.

*Significant between-group difference at 0.05 level.

adverse events, this was the case in both the tigecycline $(38 \%)$ and levofloxacin treatment groups $(21 \% ; P<$ $0.001)$. While rates of nausea and vomiting were reported significantly more often among tigecycline patients, most events occurred early, were of mild to moderate severity, and resolved within a few days without the need to stop the drug prematurely. However, concomitant medications for nausea/vomiting were given four times as often among tigecycline patients $(P \leq 0.0001)$. There were no significant differences between treatment groups in the frequency of serious adverse events, discontinuations, including those from adverse events, and deaths. There were 12 deaths in the study (2.8\%); none of the deaths were considered by the investigators to be related to the study drugs. The adverse event profile after tigecycline therapy in this study supports previous safety data from phase 3 studies $[21,22]$.

\section{Conclusion}

In summary, IV tigecycline was found to be generally welltolerated and comparable with respect to efficacy to IV levofloxacin in the treatment of hospitalized adult patients with CAP. Results of this phase 3 study also demonstrate that tigecycline achieved good cure rates against the most frequently encountered respiratory pathogen, $S$. pneumoniae, and against the other common respiratory pathogens, including Legionella pneumophila and other atypical organisms. Treatment of CAP is complicated by rising rates of antibiotic-resistant bacteria, and there is growing concern about widespread fluoroquinolone use and rising rates of fluoroquinolone-resistance among $S$. pneumoniae. Based on the results of this study, tigecycline may provide an alternative option for the treatment of hospitalized patients with CAP [23-25].

Table 7: Drug-Related Adverse Events that Occurred in $\geq 3 \%$ of Patients (mITT Population), Number of Patients (\%)

\begin{tabular}{|c|c|c|c|c|c|c|c|}
\hline \multirow{2}{*}{$\begin{array}{l}\text { Body System } \\
\text { Adverse Event }\end{array}$} & \multicolumn{2}{|c|}{$\begin{array}{c}\text { Tigecycline } \\
(\mathrm{N}=2 \mathrm{I} 6) \\
n(\%)\end{array}$} & \multicolumn{2}{|c|}{$\begin{array}{l}\text { Levofloxacin } \\
\left(\begin{array}{c}N=2 \text { I }) \\
n(\%)\end{array}\right.\end{array}$} & \multicolumn{2}{|c|}{$\begin{array}{c}\text { Total } \\
(\mathrm{N}=428) \\
n(\%)\end{array}$} & \multirow{2}{*}{$\begin{array}{c}\begin{array}{c}\text { Fisher Exact } \\
\text { P-Value }\end{array} \\
0.001^{*}\end{array}$} \\
\hline & 96 & 44.4 & 62 & 29.2 & 158 & 36.9 & \\
\hline Body as a whole & 10 & 4.6 & 10 & 4.7 & 20 & 4.7 & 1.000 \\
\hline Cardiovascular system & 9 & 4.2 & 5 & 2.4 & 14 & 3.3 & 0.416 \\
\hline Digestive system & 70 & 32.4 & 34 & 16.0 & 104 & 24.3 & $<0.00 I^{*}$ \\
\hline Diarrhoea & 15 & 6.9 & 14 & 6.6 & 29 & 6.8 & 1.000 \\
\hline Nausea & 54 & 25.0 & 16 & 7.5 & 70 & 16.4 & $<0.00 I^{*}$ \\
\hline Vomiting & 31 & 14.4 & 10 & 4.7 & 41 & 9.6 & $<0.001 *$ \\
\hline Haemic and lymphatic system & 7 & 3.2 & 4 & 1.9 & 11 & 2.6 & 0.544 \\
\hline Metabolic and nutritional & 15 & 6.9 & 16 & 7.5 & 31 & 7.2 & 0.854 \\
\hline
\end{tabular}

Some subjects had more than I drug-related adverse event.

*Significant between-group difference at 0.05 level. 


\section{Competing interests}

Wyeth Research funded this study. ND, NC, HG, and AC are employees of Wyeth Research. The remaining authors declare that they have no competing interests.

\section{Authors' contributions}

CT, SM, PIC, JS, MZ, and VC conducted the study, contributed to data acquisition, and reviewed and approved the draft manuscript. ND, NC, HG, and AC contributed to, reviewed, and approved the draft manuscript. All authors read and approved the final manuscript.

\section{Acknowledgements}

This study and analysis was sponsored by Wyeth Research, Collegeville, PA USA. Wyeth provided the authors with editorial support for the preparation of this publication (Upside Endeavors, LLC, Sanatoga, PA, USA). We wish to thank Ms. Denise A. Sarkozy from Wyeth Research for her statistical support and Mr. Jeff Goodrich from Wyeth Research for his programming assistance.

We also wish to thank the following tigecycline 313 study group investigators for their valuable involvement in this study: Frederique Jacobs (Brussels, Belgium), Hristo Metev (Regional Dispensary for Pulmonary Diseases with Stationary, Russe, Bulgaria), Ognyan Georgiev (Aleksandrovska Hospital, Sofia, Bulgaria), Rosen Marinov (5 $5^{\text {th }}$ Multifunctional Hospital for Active Treatment, Sofia, Bulgaria), Dimitar Popov (Ministry of Interior, Medical Institute, Sofia, Bulgaria), Slobodan Milutinovic (General Hospital Sveti Duh, Zagreb, Croatia), Visnja Skerk (Clinic for Infectious Diseases, Zagreb, Croatia), Jaromir Roubec (TRN Klinika, Ostrava-Poruba, Czech Republic), Kamil Klenha (Tabor, Czech Republic), Libor Kamenik, Praha, Czech Republic), Pavel Reiterer (Usti nad Labem, Czech Republic), Court Pedersen (Odense Universites hospital, Odense C), Denmark, Enn Pyttsep (North-Estonian Regional Hospital, Talinn, Estonia), Sulev Meriste (Tartu University Clinics, Tartu, Estonia), Torsten Bauer (Berufsgenossenschaftliche Kliniken, Bochum, Germany), Hartmut Lode (Berlin, Germany), Santiago Ewig (Bochum, Germany), Judith Lukacs (St. Janos Hospital, Budapest, Hungary), Marta Bisits (St. Borbala Hospital, Tatabanya, Hungary), Sandor Molnar (Petz Aladar Hospital, Gyor, Hungary), Janos Strausz (Pulmonology Hospital, Torokbalint, Hungary), Aurika Babjoniseva (P. Stradina Hospital, Riga, Latvia), Vanda Rapa (Hospital Gailezers, Riga, Latvia), Henrikas Kazlauskas (Klaipeda Hospital, Klaipeda, Lithuania), Marius Zolubas (Klaipeda Regional Hospital, Klaipeda, Lithuania), Marcin Regulski (Otwock, Poland), Jan Kus (Warszawa, Poland), Jerzy Liebhart (Wroclaw, Poland), Heana Rebedea (Institutul National de Boli Infectioase Matei Bas, Bucuresti, Romania), Petre lacob Calistru (Bucuresti, Romania), Coman Tanasescu (Spitalul Clinic Colentina, Bucuresti, Romania), Cristina Tanaseanu (Spitaul Clinic de Urgenta Sf. Pantelimon, Bucuresti, Romania), Alla Tsoi (City Clinical Hospital \#23 na "Medsantrud", Moscow, Russia), Anatoly Tokmalaev (Infections Clinical Hospital \#I, Moscow, Russia), Igor Bokarev (City Clinical Hospital \#20, Moscow, Russia), Natalia Sanina (Moscow Regional Research Clinical Institute n.a., Moscow, Russia), Raisa Stryuk (Moscow State Medica and Denistry University, Moscow, Russia), Vladimir Nonikov (Central Clinical Hospital, Moscow, Russia), Adriana Harnicarova (Trnava, Slovak Republic), Daniel Paulovic (Nitra, Slovak Republic), Jan Antolik (Levice, Slovak Republic), Juraj Mazal (Banska Bystrica, Slovak Republic), Christo Van Dyk (Worcester Medi-Clinic, Worcester, South Africa), Hans Snyman (Brits Medi-Clinic, Brits, South Africa), Jaco Jurgens (Bell Street Hospital, Gauteng, South Africa), Willem J. Rabie (National Hospital, Free State, South Africa), Luis Guillermo (Hospital Medico Quirurgico de Conxo, Santiago de Compostela, Spain), Valeriy Chernayk (Cherkassy Regional Hospi- tal, Cherkassy, Ukraine), Lyudmyla Yashyna (F.G. Ynovsky Institute of Phthisiology and Pulmonology, Kyiv, Ukraine), Yurii Feschenko (F.G. Ynovsky Institute of Phthisiology and Pulmonology, Kyiv, Ukraine), Ghali Iraqui (Hospital oulay Youssef, Rabat, Morocco), Johannes M. Engelbrecht (Vergelegen MediClinic, Somerset West, South Africa), Francese Gudiol (Cuitat Sanitaria I Universitaria de Bellvitge "Princeps d'Espanya", Barcelona, Spain), Vicenc Falco I Ferrer (Hospital General Vall d'Hebron, Barcelona, Spain), Prabha Adhikari (Kasturba Medical College Hospital, Mangalore, India), Preetam Kumar (SriRamachandra Medical College and Research Institute, Chennai, India), George D'Souza (St. John's Medical College Hospital, Bangaore, India), Sorin Rugina (Spitalul Clinic de Boli Infectioase Constanta, Constanta, Romania), Terezie Janaskova (Ostrava, Czech Republic), Valentina lonescu (Spitalul Clinic Nr. 3 "Dr. Victor Babes" Craiova, Craiova, Romania), Roman Kozlov (City Clinical Hospital \#I, Smolensk, Russia), and Yin-Ching Chuang (Chi Mei Medical Centre, Kan City, Taiwan).

\section{References}

I. Aleva RM, Boersma WG: [Guideline 'Diagnosis and treatment of community-acquired pneumonia' from the Dutch Thoracic Society]. Ned Tijdschr Geneeskd 2005, 149:250I-2507.

2. Woodhead M: Community-acquired pneumonia in Europe: causative pathogens and resistance patterns. Eur Respir J Suppl 2002, 36:20s-27s.

3. Viegi G, Pistelli R, Cazzola M, Falcone F, Cerveri I, Rossi A, Ugo Di Maria G: Epidemiological survey on incidence and treatment of community acquired pneumonia in Italy. Respir Med 2006, 100:46-55.

4. Fine MJ, Smith MA, Carson CA, Mutha SS, Sankey SS, Weissfeld LA, Kapoor WN: Prognosis and outcomes of patients with community-acquired pneumonia. A meta-analysis. JAMA 1996, 275:|34-|4|.

5. Bartlett JG, Dowell SF, Mandell LA, File TM Jr, Musher DM, Fine MJ: Practice guidelines for the management of communityacquired pneumonia in adults. Infectious Diseases Society of America. Clin Infect Dis 2000, 3 I:347-382.

6. Marrie TJ, Peeling RW, Fine MJ, Singer DE, Coley CM, Kapoor WN: Ambulatory patients with community-acquired pneumonia: the frequency of atypical agents and clinical course. Am J Med 1996, 101:508-515.

7. File TM Jr, Garau J, Blasi F, Chidiac C, Klugman K, Lode H, Lonks JR, Mandell L, Ramirez J, Yu V: Guidelines for empiric antimicrobial prescribing in community-acquired pneumonia. Chest 2004, 125:1888-1901.

8. Mandell LA, Bartlett JG, Dowell SF, File TM Jr, Musher DM, Whitney $C$ : Update of practice guidelines for the management of community-acquired pneumonia in immunocompetent adults. Clin Infect Dis 2003, 37:405- I433.

9. Niederman MS, Mandell LA, Anzueto A, Bass JB, Broughton WA, Campbell GD, Dean N, File MJ, Gross PA, Martinez F, Marrie TJ, Plouffe JF, Ramirez J, Sarosi GA, Torres A, Wilson R, Yu VL: Guidelines for the management of adults with communityacquired pneumonia. Diagnosis, assessment of severity, antimicrobial therapy, and prevention. Am J Respir Crit Care Med 2001, 163:1730-1754.

10. Woodhead M, Blasi F, Ewig S, Huchon G, leven M, Ortqvist A, Schaberg T, Torres A, Heijden G van der, Verheij TJ: Guidelines for the management of adult lower respiratory tract infections. Eur Respir J 2005, 26: I I38-1 I80.

II. Felmingham D: Comparative antimicrobial susceptibility of respiratory tract pathogens. Chemotherapy 2004, 50(Suppl I):3-10.

12. Gordon KA, Biedenbach DJ, Jones RN: Comparison of Streptococcus pneumoniae and Haemophilus influenzae susceptibilities from community-acquired respiratory tract infections and hospitalized patients with pneumonia: five-year results for the SENTRY Antimicrobial Surveillance Program. Diagn Microbiol Infect Dis 2003, 46:285-289.

13. Johnson DM, Stilwell MG, Fritsche TR, Jones RN: Emergence of multidrug-resistant Streptococcus pneumoniae: report from the SENTRY Antimicrobial Surveillance Program (1999-2003). Diagn Microbiol Infect Dis 2006, 56:69-74. 
14. Whitney CG, Farley MM, Hadler J, Harrison LH, Lexau C, Reingold A, Lefkowitz L, Cieslak PR, Cetron M, Zell ER, Jorgensen JH, Schuchat A: Increasing prevalence of multidrug-resistant Streptococcus pneumoniae in the United States. N Engl J Med 2000, 343:1917-1924.

I5. Hoban DJ, Biedenbach DJ, Mutnick AH, Jones RN: Pathogen of occurrence and susceptibility patterns associated with pneumonia in hospitalized patients in North America: results of the SENTRY Antimicrobial Surveillance Study (2000). Diagn Microbiol Infect Dis 2003, 45:279-285.

16. Fine MJ, Auble TE, Yealy DM, Hanusa BH, Weissfeld LA, Singer DE, Coley CM, Marrie TJ, Kapoor WN: A prediction rule to identify low-risk patients with community-acquired pneumonia. $N$ Engl J Med 1997, 336:243-250.

17. Lim WS, Eerden MM van der, Laing R, Boersma WG, Karalus N Town GI, Lewis SA, Macfarlane JT: Defining community acquired pneumonia severity on presentation to hospital: an international derivation and validation study. Thorax 2003, 58:377-382.

18. Fritsche TR, Sader HS, Stilwell MG, Dowzicky MJ, Jones RN: Antimicrobial activity of tigecycline tested against organisms causing community-acquired respiratory tract infection and nosocomial pneumonia. Diagn Microbiol Infect Dis 2005, 52:187-193.

19. Ko KS, Song JH, Lee MY, Park S, Kwon KT, Heo ST, Ryu SY, Oh WS Peck KR, Lee NY: Antimicrobial activity of tigecycline against recent isolates of respiratory pathogens from Asian countries. Diagn Microbiol Infect Dis 2006, 55:337-34I.

20. Olson MW, Ruzin A, Feyfant E, Rush TS 3rd, O'Connell J, Bradford PA: Functional, biophysical, and structural bases for antibacterial activity of tigecycline. Antimicrob Agents Chemother 2006, 50:2156-2166.

21. Babinchak T, Ellis-Grosse E, Dartois N, Rose GM, Loh E: The efficacy and safety of tigecycline for the treatment of complicated intra-abdominal infections: analysis of pooled clinical trial data. Clin Infect Dis 2005, 4 I (Suppl 5):S354-S367.

22. Ellis-Grosse EJ, Babinchak T, Dartois N, Rose G, Loh E: The efficacy and safety of tigecycline in the treatment of skin and skinstructure infections: results of 2 double-blind phase $3 \mathrm{com}$ parison studies with vancomycin-aztreonam. Clin Infect Dis 2005, 4I(Suppl 5):S34I-S353.

23. Salkind AR, Cuddy PG, Foxworth JW: Fluoroquinolone treatment of community-acquired pneumonia: a meta-analysis. Ann Pharmacother 2002, 36:1938-1943.

24. Carrie AG, Kozyrskyj AL: Outpatient treatment of communityacquired pneumonia: evolving trends and a focus on fluoroquinolones. Can J Clin Pharmacol 2006, I3:e I02-e I I I.

25. Davidson R, Cavalcanti R, Brunton JL, Bast DJ, de Azavedo JC, Kibsey $P$, Fleming C, Low DE: Resistance to levofloxacin and failure of treatment of pneumococcal pneumonia. N Engl J Med 2002, 346:747-750.

\section{Pre-publication history}

The pre-publication history for this paper can be accessed here:

http://www.biomedcentral.com/1471-2466/9/44/prepub

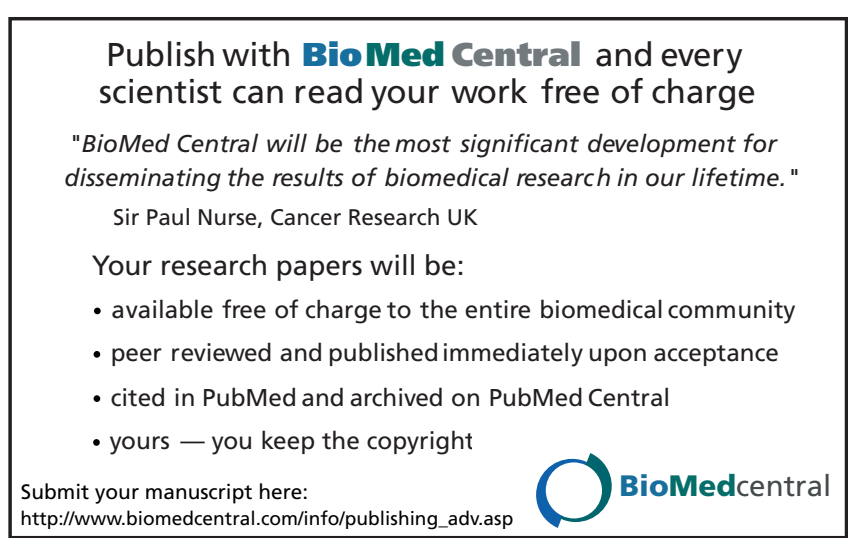

